\title{
Binocular rivalry stimuli are common but rivalry is not
}

\author{
Robert Paul O'Shea* \\ Discipline of Psychology and Cognitive Neuroscience Research Cluster, School of Health and Human Sciences, Southern Cross University, Coffs Harbour, Australia \\ *Correspondence: robert.oshea@scu.edu.au
}

\section{A commentary on}

Why is binocular rivalry uncommon? Discrepant monocular images in the real world

Arnold, D. H. (2011). Front. Hum. Neurosci. 5:116. doi: 10.3389/fnhum.2011.00116

Recently Arnold (2011) asked "Why is binocular rivalry uncommon?”. He answered in an entertainingly written, provocative article, for which I thank and congratulate him. However, I will argue that Arnold's answer falls short in two respects and his assumption that rivalry is uncommon is correct for two reasons other than the one he discusses.

Binocular rivalry is a phenomenon of human visual perception that is easy to demonstrate in the laboratory by using a stereoscope to present one image to one eye and a different image to the other: one perceives one image rather than both, and the image one perceives alternates between the two at random (Wheatstone, 1838).

In answering the question, Arnold (2011) identified two situations outside the laboratory in which the view of one eye differs from that of the other for which he claimed there is no rivalry. The first is when an object, such as the trunk of a small tree, is near both eyes as we fixate on distant objects. The trunk projects a blurry, lowcontrast, low-spatial-frequency (for which Arnold adopted Levelt's, 1968, umbrella term "stimulus strength") image onto the temporal region of the right-eye retina and onto the nasal region of the left-eye retina. In the corresponding regions of the other eye's retina, the distant objects project different, sharp images. The second is when a similar object, the tree trunk again, is closer to one eye, blocking its view. The trunk projects a blurry image onto the fovea of that eye, and the distant objects project different, sharp images onto the fovea of the other eye. In both these situations, Arnold said the sharp images dominate perception forever, preventing rivalry.
There are two problems for Arnold with these sorts of examples:

1. Although it is true that one will not immediately experience alternations between the blurry and sharp images, it is not true that there is no rivalry. Rather, the sharp images' dominating perception is a form of rivalry, wellknown from laboratory studies as permanent suppression (Ooi and Loop, 1994).

2. If one waits for long enough, the blurry image will alternate with the sharp images (cf. Blake, 1977). Indeed, George (1936) reported that the extremely lowstimulus-strength image of the back of one's closed eyelid will eventually dominate the extremely high-stimulusstrength images viewed by the open eye.

There are at least two reasons other than that Arnold offered for why rivalry is not noticed outside the laboratory:

First, although Arnold is correct that images of equal stimulus strength rarely fall on the foveae of the two eyes, it is common that images of equal stimulus strength fall on corresponding peripheral areas of the retinae. For example, as I type this on my laptop, images of the rest of the room, several meters further from my eyes than the laptop screen, fall on the retinae below the fovea. When I attend to these areas, I can see that there are burry, diplopic images there, for example the vertical edge of a fireplace appears superimposed on the horizontal edges of the bricks of the fireplace. Similarly, when I look up at the fireplace, I can see the blurry vertical edge of my laptop screen crossing the blurry horizontal edge of a nearby table. If I pay attention to these diplopic areas, I see slow alternations of binocular rivalry. Laboratory studies show that rivalry rate in peripheral vision is much slower than in central vision (e.g., Blake et al., 1992).

The ubiquity of diplopic images away from fixation was discovered by al-Haytham in the eleventh century (Alhazen, 1989).
These arise for regions off the location in space where images would be identical in the two eyes, the horopter (Aguilonius, 1613; Panum, 1858; Ogle, 1953). Binocular rivalry could be common off the horopter - it is simply not noticed.

In both situations Arnold describes, the tendency is for one to look at the nearby object (Mandelbaum, 1960), bringing identical sharp images onto the foveae. What is needed to resolve the issue of the ecological optics of binocular vision, rather than examples, is for them to be quantified by sampling the images the real world presents (cf. Howe and Purves, 2002; Howe and Purves, 2005).

Second, the eyes move about three times a second (e.g., Otero-Millan et al., 2008). This potentially places fresh images on each retinal region at the same rate. In the laboratory, these are likely to be similar to the previous images (because rival stimuli tend to be two-dimensional stimuli that display rivalry information wherever we look at them). But outside the laboratory, these images could be quite different during each fixation, and may be identical for some corresponding retinal regions. That is, any pair of corresponding retinal regions might have rival images for one fixation and similar, fusible images for the next. We know from laboratory research that turning on rival images briefly and turning them off for longer prevents rivalry from occurring by creating fusion of the two eyes' views (Dawson, 1915-1917; Kaufman, 1963; Wolfe, 1983; O'Shea and Crassini, 1984). Moreover, interspersing periods of fusion with periods of rivalry tends to prevent rivalry by promoting fusion (Julesz and Tyler, 1976; Buckthought et al., 2008).

In conclusion, Arnold (2011) posed an interesting question of why we do not notice rivalry when we look at the visual world outside the laboratory. In answering it, he identified two situations in which different strength images are projected into the two eyes, and claimed that rivalry does not occur. I have argued, to the contrary, that: 
- Perception in the situations Arnold identified is consistent with what we know about rivalry and offers no challenge to theory;

- Different images in the two eyes are much more common in peripheral regions of the retinae than in central vision;

- We do not notice potential rivalry in peripheral vision because it is slower than in central vision and anyway we do not attend to it; and

- Movement of the eyes prevents rivalry from developing.

\section{ACKNOWLEDGMENTS}

I am grateful to Urte Roeber for commenting helpfully on earlier version of this paper and to Derek Arnold for helpful discussion and for sharing a draft of his reply to this paper.

\section{REFERENCES}

Aguilonius, F. (1613). Opticorum libri sex. Philosophis juxta ac mathematicis utiles. Antwerp: Moreti.

Alhazen. (1989). The Optics of Ibn Al-Haytham: Books I-III: On Direct Vision. London: The Warburg Institute. [A. I. Sabra, Trans.].

Arnold, D. H. (2011). Why is binocular rivalry uncommon? Discrepant monocular images in the real world. Front. Hum. Neurosci. 5:116. doi: 10.3389/ fnhum.2011.00116

Blake, R. (1977). Threshold conditions for binocular rivalry. J. Exp. Psychol. Hum. Percept. Perform. 3, 251-257.

Blake, R., O’Shea, R. P., and Mueller, T. J. (1992). Spatial zones of binocular rivalry in central and peripheral vision. Vis. Neurosci. 8, 469-478.

Buckthought, A., Kim, J., and Wilson, H. R. (2008). Hysteresis effects in stereopsis and binocular rivalry. Vision Res. 48, 819-830.

Dawson, S. (1915-1917). The experimental study of binocular colour mixture. Br. J. Psychol. 8, 510-551.

George, R.W. (1936). The significance of the fluctuation experienced in observing ambiguous figures and in binocular rivalry. J. Gen. Psychol. 15, 39-61.

Howe, C. Q., and Purves, D. (2002). Range image statistics can explain the anomalous perception of length. Proc. Natl. Acad. Sci. U.S.A. 99, 13184-13188.

Howe, C. Q., and Purves, D. (2005). Natural-scene geometry predicts the perception of angles and line orientation. Proc. Natl. Acad. Sci. U.S.A. 102, 1228-1233.

Julesz, B., and Tyler, C. W. (1976). Neurontropy, an entropy-like measure of neural correlation, in binocular fusion and rivalry. Biol. Cybern. 23, 25-32.

Kaufman, L. (1963). On the spread of suppression and binocular rivalry. Vision Res. 3, 401-415.

Levelt, W. J. M. (1968). On Binocular Rivalry. The Hague: Mouton.

Mandelbaum, J. (1960). An accommodation phenomenon. Arch. Ophthalmol. 63, 923-926.

Ogle, K. N. (1953). Precision and validity in stereoscopic depth perception from double images. J. Opt. Soc. Am. 43, 906-913.
Ooi, T. L., and Loop, M. S. (1994). Visual suppression and its effect upon color and luminance sensitivity. Vision Res. 34, 2997-3003.

O'Shea, R. P., and Crassini, B. (1984). Binocular rivalry occurs without simultaneous presentation of rival stimuli. Percept. Psychophys. 36, 266-276.

Otero-Millan, J., Troncoso, X. G., Macknik, S. L., SerranoPedraza, I., and Martinez-Conde, S. (2008). Saccades and microsaccades during visual fixation, exploration, and search: foundations for a common saccadic generator. J. Vis. 8, 1-18. http://journalofvision. org/8/14/21/

Panum, P. L. (1858). Über die einheitliche Verschmelzung verschiedenartiger Netzhauteindrucke beim Sehen mit zwei Augen. Kiel.

Wheatstone, C. (1838). Contributions to the physiology of vision - Part the First. On some remarkable, and hitherto unobserved, phenomena of binocular vision. Philos. Trans. R. Soc. Lond. B Biol. Sci. 128, 371-394.

Wolfe, J. M. (1983). Influence of spatial frequency, luminance and duration on binocular rivalry and abnormal fusion of briefly presented dichoptic stimuli. Perception 12, 447-456.

Received:07 November 2011; accepted:08 November 2011; published online: 24 November 2011.

Citation: O'Shea RP (2011) Binocular rivalry stimuli are common but rivalry is not. Front. Hum. Neurosci. 5:148. doi: 10.3389/fnhum.2011.00148

Copyright (C) 2011 O'Shea. This is an open-access article distributed under the terms of the Creative Commons Attribution Non Commercial License, which permits use, distribution, and reproduction in other forums, provided the original authors and source are credited. 